Original Contribution

\title{
CHRONIC ADMINISTRATION OF CRYSTAL METH IN PARALLEL WITH OXIDATIVE STRESS IMPAIRED SPATIAL MEMORY IN PREFRONTAL CORTEX OF MAIL RATS
}

\author{
S. Hatami, H. Hatami ${ }^{*}$, F. Sheikhzade, G. Dehghan \\ Department of Animal Biology, Faculty of Natural Science, University of Tabriz, Tabriz, Iran
}

\begin{abstract}
Methamphetamine has neurotoxic effects on serotonergic, dopaminergic systems. These systems are responsible for learning and memory functions. Also oxidative stress is known to play a prominent role in the neurocognitive deficit, so the aim of present study is evaluates the effect of crystal meth on spatial learning and memory in parallel with oxidative stress parameters. 28 Male mice were randomly divided into 4 groups, including (I: sham, saline), (II: crystal meth $5 \mathrm{mg} / \mathrm{kg}$ ), (III: crystal meth $10 \mathrm{mg} / \mathrm{kg}$ ); and (IV: crystal meth $15 \mathrm{mg} / \mathrm{kg})(\mathrm{n}=7)$. Characteristics of learning and spatial memory were assessed using Morris Water Maze (MWM). Malondialdehyde (MDA), superoxide dismutase (SOD) and catalase (CAT) were assayed in all groups. Data analysis was performed by using one way ANOVA. Crystal meth reduced spatial memory and this reduction in the dose of $15 \mathrm{mg} / \mathrm{kg}$ was very high $(\mathrm{p}<0.001)$. The level of malondialdehyde increased in crystal meth $15 \mathrm{mg} / \mathrm{kg}(\mathrm{P}<0.001)$. Significant elevation in SOD activity was shown in crystal meth $15 \mathrm{mg} / \mathrm{kg}(\mathrm{P}<0.05)$. The level of CAT showed dose dependently increase in all crystal meth groups $(\mathrm{P}<0.001)$. The observations reveal that crystal meth can impaired the spatial memory as well as the disturbances in oxidative stress in the prefrontal cortex of rats.
\end{abstract}

Key words: Crystal meth, oxidative stress, spatial memory, prefrontal cortex.

\section{INTRODUCTION}

Methamphetamine (MA) is an attractive drug of abuse with easy availability because of inexpensive production and distribution of the drug in various communities (1). Cerebral vasculitis, cerebrovascular accidents due to hemorrhage or vasospasm, cerebral edema, seizures and death have also been reported in amphetamine abusers (2). The effects of MA in the central nervous system are mediated mainly by its effects on stimulation of the monoaminergic dopamine, norepinephrine, and serotonin systems. Levels of specific monoamines increase in a regionally dependent manner, based partly on the local density of monoamine terminals. Crystal meth is short for crystal meth amphetamine. The acute and chronic effects of methamphetamine are different. In general methamphetamine by

*Correspondence to: H. Hatami, Department of Animal Biology, Faculty of Natural Science, University of Tabriz, Tabriz, Iran, homeirahatami@yahoo.com

Trakia Journal of Sciences, Vol. 14, № 2, 2016 depleting serotonin and dopamine vesicles in serotonergic and dopaminergic axon terminals resulted in memory reduction (3). Short term and long term effects of methamphetamine is different. Acute MA was shown to produce improvements in cognitive processing when given to drug-naive subjects (4). In contrast, more recent studies have shown that long-term MA use is associated with impaired performance on a number of cognitive tasks (5-6). It has been concluded that acute cognitive effect of therapeutic dose of MA tend to increase attentiveness and speed of processing, but also decrease ability to filter information (7). So the neurobehavioral effects of methamphetamine depends on: time course usage and dose. It is well known that amphetamine induces an acute and rapid release of both 5-HT and dopamine from nerve endings, which may undergo oxidative deamination by monoamine oxidase (MAO), leading to the formation of deleterious amount of hydrogen peroxidase $\left(\mathrm{H}_{2} \mathrm{O}_{2}\right)$ (8). The $\mathrm{O}$-quinones metabolites of methamphetamine are 
highly redox cycling, generating semiquinone radicals and leading to the formation of reactive oxygen species (ROS) and reactive species (9). Since the reactive O-quinone intermediates are electrophilic compounds, cellular damage can occure through alkylation of crucial cellular proteins and or/ DNA (10). Therefore amphetamine metabolites can be major effectors of amphetamine neurotoxic effects, though the mechanisms behind their toxicity remain to be clarified. Some of the damages to the central neural system that are observed following amphetamine and methamphetamine (MA) administration are known to be linked to increased formation of free radicals. It has been well document that oxidative damage plays an important role in the pathogenesis of various CNS disorders and neurobehavioral impairments. There is good evidence that oxidative stress and reaction oxygen species (ROS) contribute in the learning and memory impairments (11). Also several studies link the formation of reactive oxygen species (ROS) to the CNS neurotoxicity following administration of MA, which is an amphetamine stimulate (1213). SOD is the first step of the defense system against oxidative stress, which is an important free radical scavenging action. The current study performed to determine the activity of antioxidant enzymes including SOD and CAT to assess the effects on ROS, and MDA level as an indicator of oxidative damage or lipid peroxidation in rat brain after crystal meth administration (14). Previous studies found that hippocampus and prefrontal cortex (PFC) were involved in the modulation of different processes of spatial learning and memory (15). Spatial learning and memory in the Morris water maze (MWM) is linked to prefrontal cortex function (16). Based on the putative involvement of learning and memory system in drug addiction in the current study, we tested the hypothesis that adult male rats exposed to a repeated different neurotoxic doses of crystal meth $(5,10$ and 15 $\mathrm{mg} / \mathrm{kg}$ ) daily for 5 consecutive days, would exhibit impairment in spatial memory in parallel with a alterations in oxidative stress parameters.

\section{MATERIALS AND METHODS Animals}

28 Adult male Wistar rats weighing 200-250 g (The animal house of Tabriz University of medical sciences) were housed in standard hygienic plastic ( 7 in each cages) under a $12-\mathrm{h}$ light/dark cycle (lights on at 07:00 a.m.) in a room with controlled temperature $\left(23 \pm 2{ }^{\circ} \mathrm{C}\right)$.
HATAMI S., et al Food and water were available ad libitum. The experiments were carried out during the light phase of the cycle. All animal procedures were performed according to the National Institutes of Health's Guide for the care and use of laboratory animals. Efforts were made to minimize the number of animals used and their suffering. The animals were randomly divided into following groups (7 animals per group): I (sham, saline); II (crystal meth $5 \mathrm{mg} / \mathrm{kg}$ ); III (crystal meth 10 $\mathrm{mg} / \mathrm{kg}$ ); and IV (crystal meth $15 \mathrm{mg} / \mathrm{kg}$ ). All drugs were injected intra peritoneally (i.p) at 1 $\mathrm{ml} / \mathrm{kg}$ body weight.

\section{Crystal meth administration:}

Crystal meth dependence was induced by an intraperitoneal injection of different doses of Crystal meth $(5,10,15 \mathrm{mg} / \mathrm{kg})$ for 5 consecutive days.

\section{Morris water maze testing}

Characteristic of learning and spatial memory was evaluated using Morris Water Maze for 6 consecutive days following the treatment period. Morris water maze (MWM) consists of a circular pool $(136 \mathrm{~cm}$ in diameter and $60 \mathrm{~cm}$ in height) that was filled with opaque water $\left(20 \pm 1{ }^{\circ} \mathrm{C}\right)$ and a hidden platform which was located in a fixed spot. The walls of the pool and the platform were dyed black to conceal the platform. Four positions around the edge of the tank were arbitrarily designated north $(\mathrm{N})$, south $(\mathrm{S})$, east (E) and west (W) to provide four alternative start positions, and define the division of the pool into four quadrants. The escape platform $(10 \mathrm{~cm}$ diameter) was placed at the midpoint of one of the quadrants, $2 \mathrm{~cm}$ below water surface. A video camera was mounted directly above the tank to record the rats' swim paths. The parameters escape latency (i.e., time to reach the platform, in seconds), the path length (i.e., distance traveled to reach the platform, in centimeters) and swimming speed were analyzed for all 5 days. The animals were given four $60-$ second training trials each day, over 6 consecutive days. For each training trial, the rats were placed in the water facing the pool wall at one of the four starting positions (N, S, E and W, varied from trial to trial in a pseudorandom order) and were given $60 \mathrm{~s}$ to reach the platform. Rats were carefully guided by hand to the platform if they failed to locate it within $60 \mathrm{~s}$. Regardless of success or failure to reach the hidden platform; all rats were left on the platform for $15 \mathrm{~s}$ during the inter-trial interval and then placed in their heated cage until their next trial on the next day (17). 
Measurements of oxidative stress markers in the prefrontal cortex

After termination of behavioral testing days, rats were killed by decapitation and the brains were quickly removed and kept at $-80{ }^{\circ} \mathrm{C}$ until used for preparation of homogenates. At the day of analysis, the prefrontal cortex tissues were homogenized in cold $\mathrm{KCl}$ solution (1.15\%) to give a $10 \%$ homogeny suspension and used for biochemical assays.

\section{Lipid peroxidation assay}

Malondialdehyde (MDA) results from degradation of polyunsaturated fatty acids. The production of this substance is used as a biomarker to measure the level of lipid peroxidation. MDA reacts with thiobarbituric acid (TBA) as a thiobarbituric acid reactive substance (TBARS) to form a 1:2 MDA-TBA adduct, which absorbs at $535 \mathrm{~nm}$. Thus, the quantity of TBARS is proportional to the amount of MDA. Concentration of TBARS is determined according to the method of Mihara and Uchiyama (1978). Briefly, $3 \mathrm{ml}$ of $1 \%$ phosphoric acid and $1 \mathrm{ml}$ of $0.6 \% \mathrm{w} / \mathrm{v}$ TBA aqueous solution were added to $0.5 \mathrm{ml}$ of homogenate supernatant and heated for $45 \mathrm{~min}$ in a boiling water bath. After cooling, $4 \mathrm{ml} \mathrm{n}$ butanol was added; the mixture was shaken and then centrifuged at $3,000 \times \mathrm{g}$ for $10 \mathrm{~min}$. Then the absorbance of the samples at $535 \mathrm{~nm}$ was measured. The concentration of TBARS was calculated using the MDA standard curve and is represented as $\mathrm{nmol} / \mathrm{mg}$ of protein (18).

\section{Superoxide dismutase (SOD) assay}

SOD activity in the hippocampus homogenates was assayed using a method based on the ability of the enzyme to inhibit the autoxidation of pyrogallol. Briefly, $1 \mathrm{ml}$ of Tris- $\mathrm{HCl}(45 \mathrm{mM})$ buffer containing EDTA was mixed with $5 \mu \mathrm{l}$ of homogenate supernatant and was placed in the spectrophotometer. The unit was autozerod at $420 \mathrm{~nm}$ and then $50 \mu \mathrm{l}$ of pyrogallol $(0.2 \mathrm{mM})$ was added to the above solution and quickly the absorbance of samples was measured at $420 \mathrm{~nm}$ every 15 seconds, up to two minutes. The inhibition of pyrogallol autoxidation is proportionate to the activity of SOD present in the sample. Enzyme inhibitory capacity is defined as one unit of SOD (19).

\section{Catalase (CAT) assay}

CAT activity was determined according to (1984). Briefly, hydrogen peroxide $(20 \mathrm{mM})$ in a phosphate buffer (50mM. pH 7.2) was used as hydrogen peroxide substrate and decrease of the
HATAMI S., et al

Statistical analysis substrate in $\mathrm{H} 2 \mathrm{O} 2$ concentration at $25^{\circ} \mathrm{C}$ was followed spectrophotometrically at $240 \mathrm{~nm}$ for $1 \mathrm{~min}$. Activity of the enzyme was expressed in units per $\mathrm{mg}$ of protein, with 1 unit equaling the amount of enzyme that degrades $1 \mu \mathrm{m} \quad \mathrm{H} 2 \mathrm{O} 2$ in a minute (20).

\section{Statistical analysis}

The values were presented as mean \pm standard error of the mean (S.E.M). Statistical differences were analyzed using a one-way ANOVA followed by Tukey test at the 0.05 level of significance.

\section{RESULTS}

1. Analysis of spatial memory in crystal meth treated animals:

A- Effect of different doses of crystal meth on the escape latency to find hidden platform:

One way ANOVA analysis revealed that the escape latencies were significantly different between the crystal 5, 10, 15 and saline groups. As are shown in Figure 1A we observed significant difference between crystal $5 \mathrm{mg} / \mathrm{kg}$ and salin group on day $2(\mathrm{p}<0.01)$, and on day 3 $(\mathrm{p}<0.001)$. Significant different between crystal 10 and crystal $15 \mathrm{mg} / \mathrm{kg}$ with salin observed on day 2,3 and $4(\mathrm{p}<0.001)$. Also significant difference between crystal $15 \mathrm{mg} / \mathrm{kg}$ with salin has been observed on day $5(\mathrm{p}<0.001)$.

Significant difference between crystal $5 \mathrm{mg} / \mathrm{kg}$ with crystal 10 has been observed on day 4 $(\mathrm{p}<0.05)$, and Also significant difference between crystal $5 \mathrm{mg} / \mathrm{kg}$ with crystal 15 has been observed on day $4(\mathrm{p}<0.01)$, and on day 5 $(\mathrm{p}<0.001)$. As well as significant difference between crystal $10 \mathrm{mg} / \mathrm{kg}$ with crystal 15 has been observed on day $5(\mathrm{p}<0.01)$.

\section{B-Effect of different doses of crystal meth on the traveled distance to find hidden platform:}

As are shown in Figure 1B we observed no significant difference between crystal $5 \mathrm{mg} / \mathrm{kg}$ and salin group on any day. Also significant difference between crystal $10 \mathrm{mg} / \mathrm{kg}$ with salin group was observed on day $2(\mathrm{p}<0.01)$, and on day 4 $(p<0.001)$. Significant difference between crystal $15 \mathrm{mg} / \mathrm{kg}$ with salin observed on day $1(\mathrm{p}<0.01)$. Also significant difference between crystal 5 $\mathrm{mg} / \mathrm{kg}$ with crystal 10 was observed on day 2 $(\mathrm{p}<0.05)$, on day $1 \quad(\mathrm{p}<0.01)$, and on day 3 $(\mathrm{p}<0.001)$. And also significant difference between crystal $10 \mathrm{mg} / \mathrm{kg}$ with crystal 15 observed on days $1,2(\mathrm{p}<0.001)$ and on day $4(\mathrm{P}<0.01)$. 


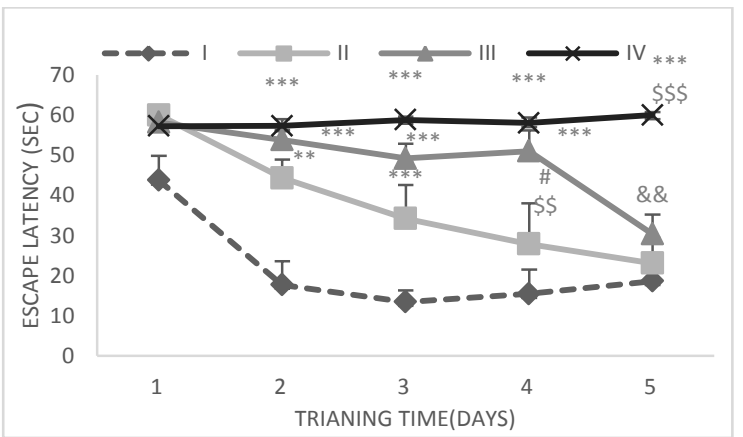

Figure 1 (A). Effect of different doses of crystal meth on the escape latency to find hidden platform in 5 consecutive days. Groups: (I: sham, saline), (II: crystal meth $5 \mathrm{mg} / \mathrm{kg}$ ), (III: crystal meth $10 \mathrm{mg} / \mathrm{kg}$ ); and (IV: crystal meth $15 \mathrm{mg} / \mathrm{kg})$. Data represent means \pm S.E.M $(\mathrm{n}=6) .{ }^{* *}(\mathrm{p}<0.01),{ }^{* * *}(\mathrm{p}<0.001)$ significant difference when compared with saline group. \# $(\mathrm{p}<0.05)$ represent significant difference between crystal 5 and crystal $10 \mathrm{mg} / \mathrm{kg}$ on day 4 . $\$ \$$ $(\mathrm{p}<0.01)$ significant different when compared crystal 5 and crystal 15 on day 4 and $\$ \$ \$(p<0.001)$ represent significant difference between crystal 5 and crystal $15 \mathrm{mg} / \mathrm{kg}$ on day $5 . \& \&$ (p<0.01) represent significant difference between crystal 10 and crystal $15 \mathrm{mg} / \mathrm{kg}$ on day5.

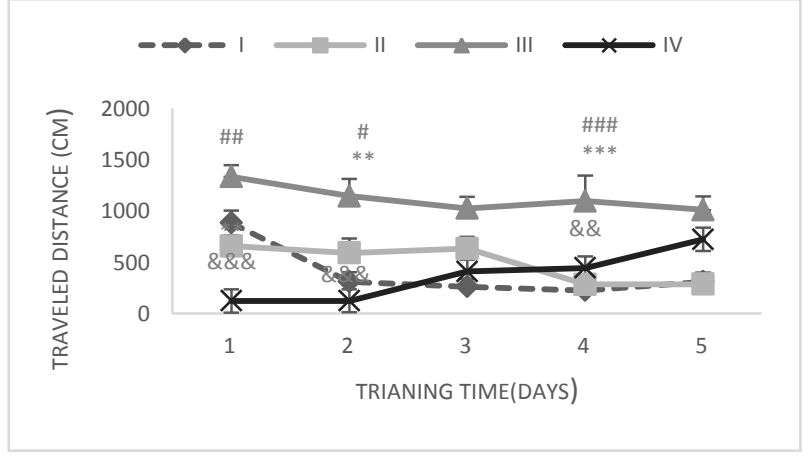

Figure 1 (B). Effect of different doses of crystal meth on the traveled distance to find hidden platform in 5 consecutive days. $* *(\mathrm{p}<0.01), * * *(\mathrm{p}<0.001)$ significantly different when compared with saline group. \# $(\mathrm{p}<0.05)$, $\# \#(p<0.01)$, \#\#\# ( $<<0.001)$ represent significant difference between crystal 5 and crystal $10 \mathrm{mg} / \mathrm{kg}$ on day1, 2 and 4. $\& \&(\mathrm{p}<0.01), \& \& \&(\mathrm{p}<0.001)$ represent significant difference between crystal 10 and crystal $15 \mathrm{mg} / \mathrm{kg}$ on day 1,2 and 4 .

\section{C-Effect of different doses of crystal meth on \\ the swimming speed to find hidden platform:}

and salin group on day1 $(\mathrm{p}<0.01)$, and significant difference between crystal $5 \mathrm{mg} / \mathrm{kg}$ and crystal As are shown in Figure $\mathbf{1 C}$ we observed 10 has been observed on day $5(\mathrm{p}<0.05)$. significant difference between crystal $5 \mathrm{mg} / \mathrm{kg}$

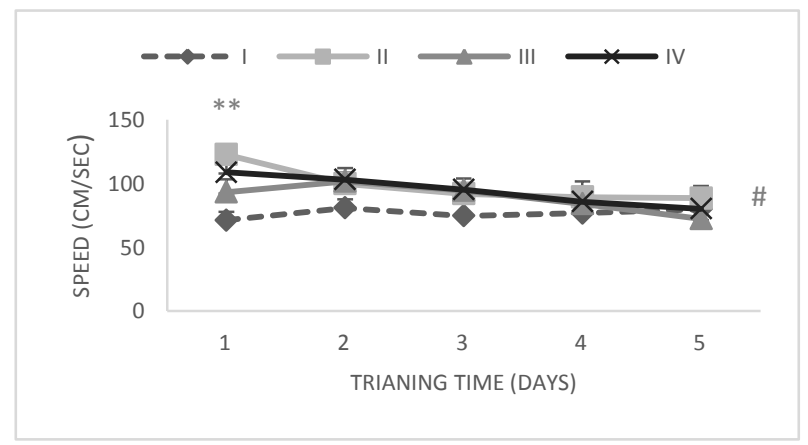

Figure $1(\mathbf{C})$. Effect of different doses of crystal meth on the swimming speed to find hidden platform in 5 consecutive days. $* *(p<0.01)$ significantly different when compared with saline group. $\#(p<0.05)$ represent significant difference between crystal 5 and crystal $10 \mathrm{mg} / \mathrm{kg}$. 


\section{Analysis of oxidative stress parameters in crystal meth treated animals:}

\section{A. Effect of different doses of crystal meth on the lipid peroxidation (MDA)}

HATAMI S., et al

As are shown in Figure 2A, there are significant difference in malondialdehyde (MDA) level between dose of crystal meth $15 \mathrm{mg} / \mathrm{kg}$ with slain group $(\mathrm{p}<0.001)$. Significant difference between crystal $5 \mathrm{mg} / \mathrm{kg}$ with crystal 15 has been observed $(\mathrm{p}<0.01)$.

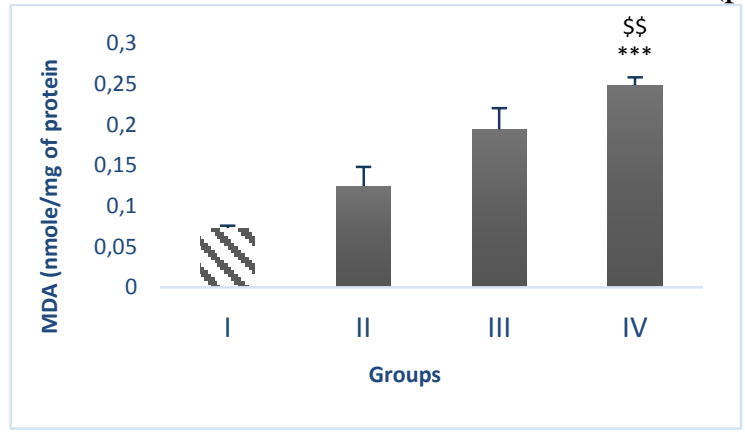

Figure 2 (A). Effect of different doses of crystal meth on the MDA levels in prefrontal cortex. $* * *(p<0.001)$ significantly different when compared with saline group. $\$ \$(\mathrm{p}<0.01)$ represent significant difference between crystal 5 and crystal $15 \mathrm{mg} / \mathrm{kg}$.

\section{B. Effect of different doses of crystal meth on the antioxidant enzyme SOD}

difference in SOD activity between crystal 5 As are shown in Figure $\mathbf{2} \mathbf{B}$, there are significant difference in SOD activity between crystal meth $15 \mathrm{mg} / \mathrm{kg}$ with salin group $(\mathrm{p}<0.05)$. Significant

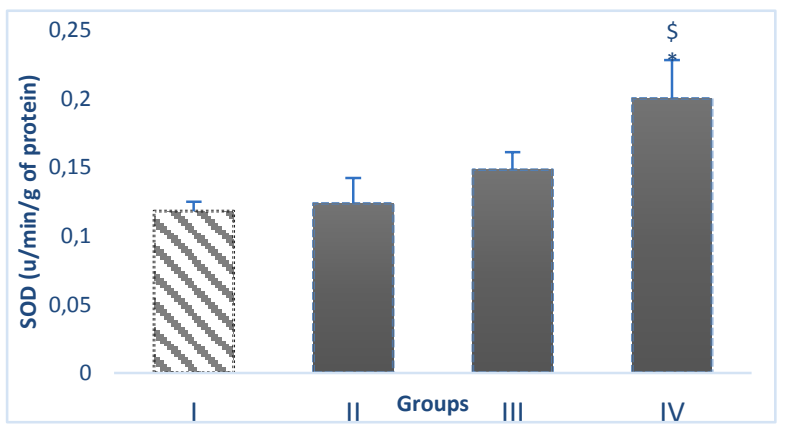

Figure 2 (B). Effect of different doses of crystal meth on the SOD levels in prefrontal cortex. * $(\mathrm{p}<0.05)$ significantly different when compared with saline group. $\$(\mathrm{p}<0.05)$ represent significant difference between crystal 5 and crystal $15 \mathrm{mg} / \mathrm{kg}$.

\section{Effect of different doses of crystal meth on the antioxidant enzyme CAT}

As are shown in Figure $\mathbf{2} \mathbf{C}$, there are significant difference in CAT activity between saline group and crystal $10 \quad(\mathrm{p}<0.05)$, and crystal 15 $(\mathrm{p}<0.001)$. Significant difference in CAT activity between crystal $5 \mathrm{mg} / \mathrm{kg}$ with crystal $10(\mathrm{p}<0.05)$ was observed. Significant difference between crystal $5 \mathrm{mg} / \mathrm{kg}$ with crystal 15 observed $(p<0.001)$. Also significant difference between crystal $10 \mathrm{mg} / \mathrm{kg}$ with crystal 15 was observed $(\mathrm{p}<0.01)$.

\section{DISCUSSION}

In the present study, 3 doses of crystal meth (5, 10 and $15 \mathrm{mg} / \mathrm{kg}$ ) comparatively were used in evaluating memory impairment. Our results showed crystal meth in 3 doses had an increased escape latency time and traveled distance to find hidden platform in a MWM task. The impairing effect crystal meth on spatial memory was dose dependent, so that crystal meth $15 \mathrm{mg} / \mathrm{kg}$ had severe neurotoxic effect on spatial memory. It has been shown that high doses of crystal meth (15 and $20 \mathrm{mg} / \mathrm{kg}$ ) in early days of gestation impair spatial memory in the Morris water maze (MWM), while lower doses $(5,10 \mathrm{mg} / \mathrm{kg}) \mathrm{did}$ not have any effect on cognition in adult offspring (21). In our previous study it has been shown that crystal meth in the doses of $(5,10$ and $15 \mathrm{mg} / \mathrm{kg}$ ) impaired short term memory by using shuttle box setup. Crystal meth $15 \mathrm{mg} / \mathrm{kg}$ showed most severe impairing effect on memory retention (22). The effect of amphetamine on 
HATAMI S., et al

cognitive functions depends on the protocol of dose and time course administration. So based on these two main factors, there are many contradictory studies in this field. Therefore

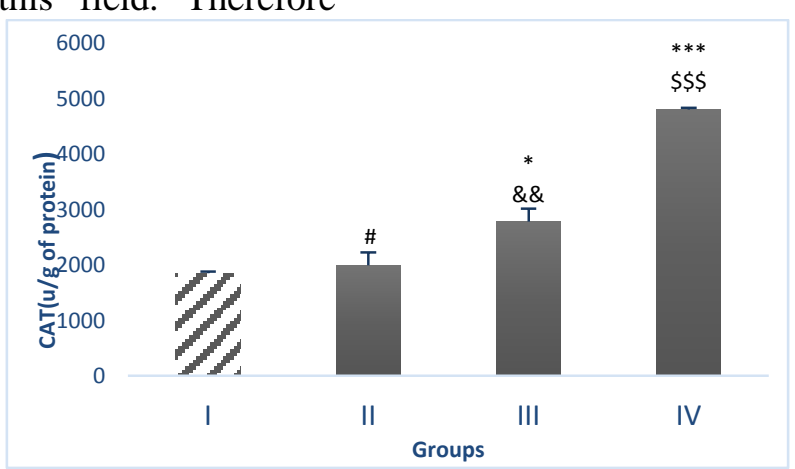

Figure 2 (C). Effect of different doses of crystal meth on the CAT levels in prefrontal cortex. * ( $\mathrm{p}<0.05)$, *** $(p<0.001)$ significantly different when compared with saline group. \# $(p<0.05)$ represent significant difference between crystal 5 and crystal $10 \mathrm{mg} / \mathrm{kg}$. $\$ \$ \$(\mathrm{p}<0.001)$ represent significant difference between crystal 5 and crystal $15 \mathrm{mg} / \mathrm{kg}$. \&\& ( $<<0.01)$ represent significant difference between crystal 10 and crystal $15 \mathrm{mg} / \mathrm{kg}$.

Previous studies mainly focused on the neurotoxic effects of crystal meth, which found that high doses of crystal meth impaired spatial learning ability and recognition memory (23). Impaired recognition memory and spatial memory was also detected in animals experienced repeated (once daily for 5-7 days) low dose (1.0 mg/kg) MA treatments (24). Besides, low dose MA administration was reported to improve memory in human addicts (25) and also in animal models. However, there were few studies about how MA modulates spatial learning and memory when it was given during different phases of memory formation and during reconsolidation (26). Both hippocampus and prefrontal cortex are regions important in spatial learning and memory in humans and rodents (27-29). Extensive destruction of hippocampal pyramidal cells by MA would have affected the ability of exposed rats to correctly navigate in the maze and this could also have contributed to their poor performance on the maze. Histological study clearly support earlier reports that crystal meth extensively destroys hippocampal neurons (30) and that crystal meth induces neurotoxicity in the brain. High doses of crystal meth disrupt blood brain barrier in the limbic regions producing extensive neuronal degeneration in the hippocampus, leading to learning and memory loss (30). Also it has been reported that animals administered with crystal meth $(10 \mathrm{mg} / \mathrm{kg})$ of three days alone showed significantly longer latency and reduced number of times they located the platform during the probe trial after administration. This indicates poorer learning and memory capacity (31). Therefore the present studies have shown that crystal meth negatively affects learning and memory. In the other part of this study we tested the hypotheses that crystal meth- induced neurotoxicity may be linked to the oxidative stress parameters within the prefrontal cortex. In fact some of the damages to the central neural system that are observed following amphetamine and methamphetamine (MA) administration are known to be linked to increased formation of free radicals. Free radicals have relatively short half-lives, and thus the determination of their levels is difficult. Therefore, they can be evaluated indirectly by measurement of some antioxidant enzyme levels such as superoxide dismutase (SOD), catalase (CAT), by products of lipid peroxidation such as (MDA). The present study focused on evaluation of lipid oxidation and antioxidant defense mechanisms and examined the amount of MDA formation, which is an end product of membranes fatty acid peroxidation (32) and the activity level of CAT and SOD, which is the enzyme that scavenges superoxide anions (33). According to our results, the level of MAO, as a lipid peroxidation index increased in crystal meth group $15 \mathrm{mg} / \mathrm{kg}$ when compared with control group. Also we found a significant elevation in SOD level only in crystal meth 15 $\mathrm{mg} / \mathrm{kg}$. The level of CAT shown dose dependently increase in all crystal meth groups. In the current study, the significantly elevated MDA activity in rat prefrontal cortex administered $15 \mathrm{mg} / \mathrm{kg}$ crystal meth for 5 days 
HATAMI S., et al

showed that this crystal meth might have an effect of increasing lipid peroxidation. This finding is in agreement with previous study show methamphetamine $(10 \mathrm{mg} / \mathrm{kg})$ administration significantly elevated MDA level in rat brain (34). In other methamphetamine studies, elevated TBARS levels have been indicator of lipid peroxidation following methamphetamine administration (34). In disagreement with current study, it has been shown there was no difference in MDA levels of rat brains following methamphetamine $10 \mathrm{mg} / \mathrm{kg} \quad$ (35). These findings are in agreement with previous studies showing the formation of reactive oxygen species (ROS) to the CNS neurotoxicity following administration of crystal meth. Increases in levels of various oxidation products following crystal meth administration have been reported suggesting a role for antioxidant mechanisms in reducing crystal meth -induced toxicity (36). As mentioned above in the current study crystal meth administration $(10,15 \mathrm{mg} / \mathrm{kg})$ significantly increased the level of SOD in prefrontal cortex of rat. SOD is the first step of the defense system against oxidative stress, which is an important free radical scavenging action. Our results are consistent with previous reports that methamphetamine treatment causes 1.2- fold increase in the activity of SOD (35). In other reports acute perioral administration of a single dose of 3, 4methylenedioxymethamphetamine $(5,10,20$ and $40 \mathrm{mg} / \mathrm{kg}$ ) resulted in increase of SOD (37). With the exception of brain, methamphetamines increased the activity of SOD in other tissues such as liver (38). The level of catalase (CAT) activity in our study was significantly increase dose dependently. This finding is in line with recent works showing a decrement of CAT activity by methamphetamine-induced oxidative stress (39). Also in other reports in human methamphetamine abuser, the activity of CAT was decreased in erythrocytes (40). In conclusion, our findings supports the idea that crystal meth exposure can cause a neurocognitive deficit that which indirectly correlates with oxidative stress parameters. The results obtained in the present study suggests that oxidative stress plays a crucial role in crystal meth-induced neurotoxicity and spatial memory impairment.

\section{REFERENCES}

1. Volkow, N.D., Chang, L., Wang, G., Fowler, JS., Leonido-Yee, M., Franceschi, D., Sedler, MJ., Gatley, SJ., Hitzemann, R., Ding, YS.,
Logan, J., Wong, $\mathrm{C}$ and Miller E.N., Association of dopamine transporter reduction with psychomotor impairment in methamphetamine abusers. Am. J. Psychiatry, 158: 377-382. 2001.

2. Lan, K.c., Yf, Lin., Fc, Y.u., Cs Lin and $P$ Chu Clinical manifestations and prognostic features of acute methamphetamine intoxication.. J. Formos. Med. Asso, 97: 528533. 1998.

3. Osama, S., El-Tawil, A.H., Abou-Hadeed, M.F., EL-Bab, A.A., Shalaby. DAmphetamine-induced cytotoxicity and oxidative stress in isolated rat hepatocytes. Pathophysiology, 18: 279-285.2011.

4. Rogers, R.D., Everitt, B.J., Baldacchino, A., Blackshaw, A.J., Swainson, R., Wynne, K., Baker, N.B., Hunter, J., Carthe, T., Booke,r E., London, M., Deakin, J.F., Sahakian, B.J., Robbins, T.W., Dissociable deficits in the decision-making cognition of chronic amphetamine abusers, opiate abusers, patients with focal damage to prefrontal cortex, and tryptophan-depleted normal volunteers: evidence for monoaminergic mechanisms. Neuropsychopharmacology, 20: 322-339, 1999.

5. Salo, R., Nordahl, E., Possin, K., Leamon, M., Gibson, D.R., GallowayG, P., Flynn, N.M., Henik, A., Pfefferbaum , A., Sullivan, E.V., Preliminary evidence of reduced cognitive inhibition in methamphetaminedependent individuals. Psychiatry Res, 111: 65-74, 2002.

6. Simon, S.L., Domier, C., Carnell, J., Brethen, P., Rawson, R., Ling, W., Cognitive impairment in individuals currently using methamphetamine. Am. J. Addict, 9: 222231, 2000.

7. Nagai, T., Yamada, K., Molecular mechanism for methamphetamineinduced memory impairment. Jpn J Alcohol Stud Drug Depend, 45: 81-91. 2010.

8. Cadet, J.L., Krasnova, I.N., Molecular bases of methamphetamineinduced neurodegeneration. Int Rev Neurobiol, 88: 101-119. 2009.

9. Abekawa, T., Ohmori, T., Koyama, T., Tolerance to the neurotoxic effect of methamphetamine in rats behaviorally sensitized to methamphetamine or amphetamine. Brain Res, 767: 34-44. 1997.

10. Mizoguchi, H., Takuma, K., Fukakusa, A., Ito, Y., Nakatani, A., Ibi, D., et al. Improvement by minocycline of methamphetamine-induced impairment of 
recognition memory in mice. Psychopharmacology (Berl), 196: 233-241. 2008.

11.Schreibelt, G., Van Horssen, J., Van Rossum, S., Dijkstra, C.D., Drukarch, B., Vries, H.E., Therapeutic potential and biological role of endogenous antioxidant enzymes in multiple sclerosis pathology. Brain Res. Rev, 56: 322330. 2007.

12. Acikgoz, O., Gonenc, S., Kayatekin, B.M., Uysal, N., Pekcetin, C., Semin, I., Gure, A., Methamphetamine causes lipid peroxidation and an increase in superoxide dismutase activity in the rat striatum. Brain Res, 813: 200-202. 1998.

13.Wan, F.J., Lin, H.C., Huang, K.L., Tseng, C.J., Wong, C.S., Systemic administration of D-amphetamine induces long-lasting oxidative stress in the rat striatum. Life Sci, 66: 205-212. 2000.

14.Storz, G., Imlayt, J.A., Oxidative stress, Curr. Opin. Microbiol. 2 (1999) 188-194. Sugiura, M., Saito, H., Abe, K., Shoyama, Y., Ethanol extract of Crocus sativus L. Antagonizes the inhibitory action of ethanol on hippocampal long-term potentiation in vivo, Phytother. Res, 9: 100-104. 1995.

15. Broening, H.W., Morford, L.L., InmanWood, S.L., Fukumura, M., Vorhees, C.V., 3,4-Methylenedioxymethamphetamine

(Ecstasy)-Induced Learning and Memory Impairments Depend on the Age of Exposure during Early Development. J. Neurosci, 21(9): 3228-3235. 2001.

16.McNamara, R.K., Skelton, R.W., the neuropharmacological and neurochemical basis of place learning in the Morris water maze. Brain Res Rev, 18:33-49. 1993.

17. Deng, X.h., Ai, W.m., Lei, D.l., Luo, X.g., Yan, X.X., Li, Z., Lipopolysaccharide induces paired immunoglobulin-like receptor B (PirB) expression, synaptic alteration, and learningmemory deficit in rats, Neuroscience, 209: 161-170. 2012.

18. Ghadrdoost, B., Vafaei, A.A., Rashidy-Pour, A., Bandegi, A.R., Motamedi, F., Haghighi, S., Samani, H.R., Pahlvan, S., Protective effects of saffron extract and its active constituent crocin against oxidative stress and spatial learning and memory deficits induced by chronic stress in rats, Eur. $J$ Pharmacol, 667: 222-229. 2011.

19.Gao, R., Yuan, Z., Zhao, Z., Gao, X., Mechanism of pyrogallol autoxidation and determination of superoxide dismutase
HATAMI S., et al

enzyme activity, Bioelectrochem. Bioenerg, 45: 41-45. 1998.

20.Peraile, L., Granado, N., Torres, E., Guiterrez-Lopez, M.D., Moratalla, R., Colado, M.I., Oshea, E., Cocaine potentiates MDMA-induced oxidative stress but not dopaminergic neurotoxicity in mice: implications for the pathogenesis of free radical-induced neurodegenerative disorders. Psychopharmacology (Berl), 230(1): 125-35. 2013.

21. Acuff-Smith, K.D., Schilling, M.A., Fisher, J.E., Vorhees, C.V., Stage-specific effects of prenatal d-methamphetamine exposure on behavioral and eye development in rats. Neurotoxicol. Teratol, 18: 199-215. 1996.

22.Hatami, H., Babri, Sh., Garebagei, P., Comprative study of interaperitoneal injection of ecstasy, crystal, glass and heroine on passive avoidance learning in male rats. Journal of psychology- university of Tabriz, 5 (19): 67-47. 2010.

23.Belcher, A.M., Feinstein, E.M., O’Dell, S.J., Marshall, J.F., Methamphetamine influences on recognition memory: comparison of escalating and single-day dosing regimens. Neuropsychopharmacology. 33:1453-1463. 2007. [PubMed: 17637607]

24.Schutov, B., Hrub, L., Pometlov, M., Deykun, K., Šlamberov, R., Cognitive functions and drug sensitivity in adult male rats prenatally exposed to methamphetamine. Physiological Research, 58:741-750. 2009. [PubMed: 19093723].

25.Mahoney, J.J., Jackson, B.J., Kalechstein, A.D., Garza, R.D., Newton, T.F., Acute, lowdose methamphetamine administration improves attention/information processing speed and working memory in methamphetamine-dependent individuals displaying poorer cognitive performance at baseline. Progress in NeuroPsychopharmacology and Biological Psychiatry, 35:459-465. 2010. [PubMed: 21122811].

26.Kennedy, C.D., Houmes, S.W., Wyrick, K.L., Kammerzell, S.M., Lukowiak, K., Sorg, B.A., Methamphetamine enhances memory of operantly conditioned respiratory behavior in the snail Lymnaea stagnalis. Journal of Experimental Biology, 213:2055-2065. 2010.

27.Barnes, C.A., Spatial learning and memory processes: the search for their neurobiological mechanisms in the rat. Trends Neurosc, 11: 163-169. 1988. 
28.Iaria, G., Petrides, M., Dagher, A., Pike, B., Bohbot, V. D., Cognitive strategies dependent on the hippocampus and caudate nucleus in human navigation: variability and change with practice. J. Neurosci, 23: 5945-5952. 2003.

29.Mcdonald, R.J., White, N. M., Parallel information processing in the water maze: evidence for independent memory systems involving dorsal striatum and hippocampus. Behav. Neural. Bio, 61: 260-270. 1994.

30.Nwoha, P.U., Ojo, G.B., Ajayi, S.A., Ofusori, D.A., Oluwayinka, O.P., Odukoya, S.A., Falana, B.A., Garcinia kola diet provides slight neuroprotection to mice hippocampal neurons against neurotoxin. J. Environ. Neurosci. Biomed, 1 (2): 125-136. 2007.

31. Vorhees, C.V., Inman-Wood, S.L., Morford, L.L., Broening, H.W., Fukumura, M., Moran MS Adult Learning Deficits after Neonatal Exposure to D-Methamphetamine: Selective Effects on Spatial Navigation and Memory. $J$. Neurosci, 20(12): 4732-4739. 2000.

32.Kita, T., Wagner, G.C., Nakashima, T., Current research on methamphetamineinduced neurotoxicity: animal models of monoamine disruption. J Pharmacol Sci, 92: 178- 195. 2003.

33.Cubells, J. F., Rayport, S., Rajendran, G., and Sulzer, D., Methamphetamine neurotoxicity involves vacuolation of endocytic organelles and dopamine-dependent intracellular oxidative stress. J. Neurosci, 14, 2260-2271. 1994.

34. Acikgoz, O., Gonenc, S., Kayatekin, B.M., Uysal, N., Pekcetin, C., Semin, I., Gure, A., Methamphetamine causes lipid peroxidation and an increase in superoxide dismutase activity in the rat striatum. Brain Res, 813: 200-202. 1998.

35.Cöngöloglu, A., Türkbay, T., Doruk, A., Topal, T., Savafler, A., Aydin, A., LongTerm Methylphenidate Treatment Causes Increased Superoxide Dismutase Activity and Unchanged Lipid Peroxidation in Rat Brain. Klinik Psikofarmakoloji Bülteni, 16:79-83. 2006.

36.Harold, C., Wallace, T., Friedman, R., Gudelsky, G., Yamamoto, B., Methamphetamine selectively alters brain glutathione. Eur J Pharmacol, 400: 99-102. 2000.

37.Simic, I., Malicevic, Z., The acute effects of 3, 4- methylenedioxymethamphetamine on oxidative stress in rat brain. Med Pregl, 61 (5-6). 2008.

38.NMDA-induced hepatotoxicity in rat: oxidative stress after acute and chronic administration. Vojnosanit, 61 (2): 125-31. 2004.

39.Peraile, L., Granado, N., Torres, E., Guiterrez-Lopez, M.D., Moratalla, R., Colado, M.I., Oshea, E., Cocaine potentiates MDMA-induced oxidative stress but not dopaminergic neurotoxicity in mice: implications for the pathogenesis of free radical-induced neurodegenerative disorders. Psychopharmacology (Berl), 230(1): 125-35. 2013.

40.Zhou, J.F., chen, P., Zhou, Y.H., Zhang L., Chen, H.H., (3, 4Methylenedioxymethamphetamin (MDMA) abuse may cause oxidative stress and potential free radical damage. Free Radic Res, 37 (5): 491-7. 2003. 